\title{
A Value and Model Driven Method for Patient Oriented KPI Design in Health Care
}

\author{
Erik Perjons and Paul Johannesson \\ Department of Computer and Systems Sciences, Stockholm University \\ Forum 100, SE-164 40, Kista, Stockholm, Sweden \\ \{perjons, pajo\} adsv.su.se
}

\begin{abstract}
In all societies, large resources are spent on health care. However, service quality is still unsatisfactory in large parts of the health care sector. One reason for this state of affairs is the complexity of health care organisations, which make them difficult to govern. Furthermore, due to the high degree of specialisation, health care organisations often need to cooperate, which adds to the complexity. One possible way to improve the cooperation and management of health care organisations is the use of performance management, which is a management approach aiming at optimising the performance of an organisation. The main instrument in performance management is the use of Key Performance Indicators (KPI), which measure how well an organisation fulfills its goals. Designing effective KPIs is a complex and time consuming task that requires substantial efforts. Therefore, there is a need for methods that support organisations in designing KPIs. This paper proposes a value and model driven method for identifying patient oriented KPIs.
\end{abstract}

Keywords: Performance management, KPI, Enterprise modelling, Service quality, SERVQUAL.

\section{Introduction}

Large resources are spent on health care in the European welfare society, but a number of problems still remain, including unequal access to health care, large variations in outcomes of treatments, deficiencies in service quality, and inefficient resource use. A main reason behind these problems is the complexity of the health care sector, which makes it problematic to govern. For example, health care needs to fulfill several and often contradictory goals, such as equality, high quality and efficiency. At the same time, a large number of stakeholders need to interact with each other in order to ensure the delivery of high-quality health care. Furthermore, European health care faces a period of potentially profound changes in social attitudes, demographic structure, economic conditions and medical technologies.

In order to better govern the health care sector, there is an increasing interest in performance management, which is a management approach aiming at optimising the performance of an organisation, i.e. optimising its business processes and outcomes [1]. The main activities in performance management are identifying 
business goals, developing key performance indicators (KPIs), monitoring and measuring the performance using the KPIs, analysing the results of the measurements, and acting in order to better fulfill the goals of the organisation [2]. Thus, performance management can be an approach for managing efficiency, cost, and quality in any business, including health care.

The main instrument in performance management is the KPI, which we here define as a property of a phenomenon that can be used to measure the performance of an organisation. Examples of KPIs are "sales revenue", "patient satisfaction", and "patient throughput".

KPIs operationalise business goals, i.e. vague and high-level goals can be expressed in terms of KPIs, thereby making them concrete and easy to understand [2]. For example, a goal like "Patients should get fast treatment for serious diseases" can be operationalised as "Waiting time for hip replacement surgery should be less than one month during 2010", which contain a KPI ("Waiting time for hip replacement surgery") and a target ("less than one month during 2010). Such a statement can easily be monitored and measured.

KPIs are powerful instruments for governing an organisation, as they are easily understandable, actionable, and can be effectively monitored. However, this also means that the use of inappropriate KPIs can have significant negative effects on the performance of an organisation [2]. For example, using KPIs focusing on quantity instead of quality can divert employees from paying attention to quality in products and services. Thus, it is essential to design and implement effective KPIs that actually improve the performance of an organisation in different aspects, such as efficiency, cost and quality.

Designing effective KPIs is a complex and time consuming task, which requires substantial effort from performance management experts as well as domain experts, such as health care managers, physicians and nurses [3]. In particular, it is difficult to ensure completeness in KPI design, i.e. when a set of potential KPIs have been identified, there is still a risk that relevant and effective KPIs have been omitted. Another issue in KPI design for health care is the fact that KPIs aimed at measuring service quality in many cases cannot be directly understood by patients because of the complex relationship between diagnostic and therapeutic services and their results [3]. This is different from most other industries, where service quality almost always can be directly perceived by service customers.

The goal of the paper is to propose a method for constructing a complete set of patient oriented KPIs, i.e. KPIs from the patient's perspective. KPIs measuring internal efficiency, such as revenue and cost efficiency, are not addressed in this paper.

The rest of the paper is structured as follows. Section 2 gives an overview of related work, in particular performance management and service quality analysis. Section 3 presents the method that addresses both technical and functional service quality in health care. Section 4 provides a demonstration of the method based on a case study from the eye care health sector. Finally, Section 5 summarises the results of the paper and gives suggestions for future work. 


\section{Related Work}

Performance management, i.e. measuring performance of an organisation, has been an important management instrument in business for the past 20 years [4]. In recent years the use of performance management has accelerated, as evidenced by the proliferation of performance management methods, key performance indicators (KPI), and IT support such as business intelligence and performance dashboard systems. Health care is no exception to this trend; performance management has attracted substantial attention among governmental and private funders of health care, health care providers, patient organisations as well as researchers in health care management [4]. This interest has emerged in parallel with the interest for other, and closely related, health care improvement approaches, such as accreditation, service evaluation, quality improvement, external auditing, outcome research and evidence-based medicine [4]. However, there is no clear demarcation line between these approaches and performance management, as different practitioners and researchers use different definitions and concepts.

Measuring performance is about measuring the outcomes and quality of business processes. In health care, there are two main categories of quality: technical service quality, i.e. clinical results of health services, and functional service quality, i.e. patient assessments of the quality of care [3], see also [5]. In general, technical service quality is difficult to understand and measure for both health care providers, health care funders and patients [3]. Therefore, many performance management initiatives in health care have focused on functional service quality.

A main research theme within functional service quality has been to find the right balance of service quality dimensions. As a starting point, a well-known service quality framework, SERVQUAL [6], has frequently been used. SERVQUAL measures the gap between perceived and expected service quality, using five quality dimensions: reliability, assurance, tangibles, empathy and responsiveness. Often used is also a predecessor to SERVQUAL [7], which includes ten quality dimensions. In SERVQUAL these ten dimensions were condensed to five, each with a set of sub dimensions, called items. SERVQUAL was meant to be a service quality framework independent of business area. However, when used in health care, further dimensions are often added, commonly created using focus groups with physicians, nurses, health care managers and patient representatives, see for example [8], [9], and [10]. The relationship between service quality in health care and patient satisfaction is also a complex issue, discussed in several research papers, see, for example [11].

For identifying KPIs, the most common tool is the use of goals and objectives [2]. Usually the goals and objectives of an organisation are structured graphically in goal models, visualising an hierarchy of strategic, tactical and operational goals.

Goal models are examples of enterprise models, while other examples are value models, process models, conceptual models and information models. In general, enterprise models offer graphical representations of the structure, goals, processes, information, resources, people, and constraints of an organisation. They provide compact and graphical descriptions of an organisation and its environment, which makes them ideal for supporting communication between different stakeholders. They can work as a base for creating a common understanding of the organisation, for change management, as well as for IT system design. Process and conceptual models have 
been used extensively both in health management research and health care standards and specifications, such as SAMBA, HISA, HL7, CONTSYS. Recently, using value models for analysis in health care have gained increased attention [12], [13]. In this paper, value models and conceptual models are used as the basis for identifying KPIs. To our knowledge, this has not been done in previous work.

\section{Method for Value Based KPI Identification}

The purpose of the method proposed is to assist a KPI designer in creating a set of KPIs that can be used to assess the quality of health care services from a patient point of view. An overview of the method is depicted in Fig. 1.

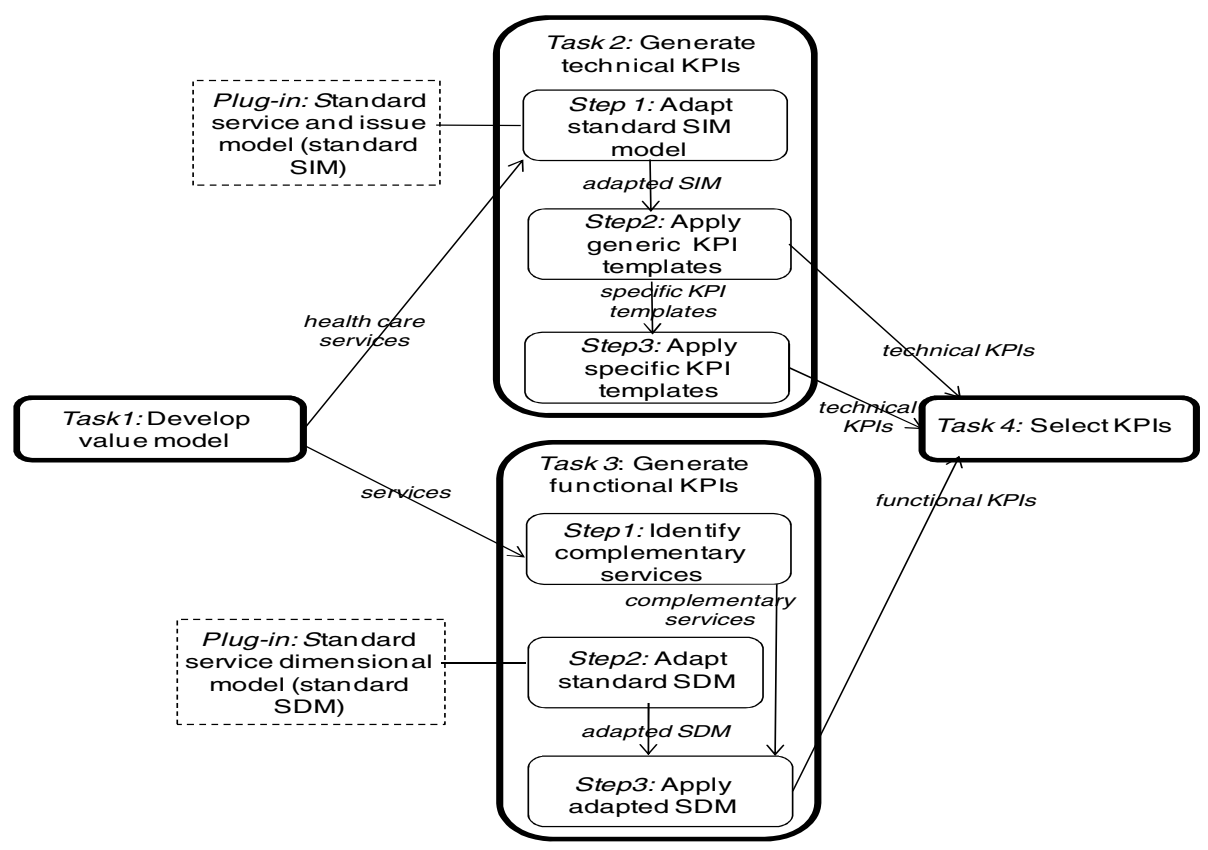

Fig. 1. A graphical overview of the method for value and model based KPI identification

The first task to be carried out is to create a value model scoping the health care scenario under consideration, thereby determining the most important health care services as well as other services in the scenario. The second task aims at generating KPIs for technical service quality that concern the results of health services and the consequences of health issues. For this task, we introduce a supporting instrument for representing relevant health care services and health issues. This instrument takes the form of a so called standard service and issue model (standard SIM), see Section 3.2, that can be modified and extended to fit the current health care scenario. The third task aims at generating KPIs for functional service quality that concern the manner in which services are delivered to patients. For this purpose, we introduce a supporting 
instrument in the form of a so called standard service dimension model (standard SDM), see Section 3.3, based on the predecessor to SERVQUAL [7], which can be modified and extended to fit the current health care scenario. Finally, there is a reviewing and filtering task, i.e. task four, where the KPIs suggested in the previous tasks are evaluated and those deemed most important are selected as candidates for implementation. Below the tasks are described in detail.

\subsection{Task 1: Develop Value Model}

A first task is to delimit the domain for which the KPIs are to be designed. For this purpose, a value model is to be created. The value model shall describe the actors of the value network under consideration, such as health care providers and patient. The value model shall also show the resource transfers between these actors, including transfers of services such as examinations and treatments. The value model will be the basis for determining health care services and other patient related services for which KPIs are to be developed. A simple example of a value model is shown in Fig. 2, which shows two actors, patient and primary health care provider, as well as their resource transfers, eye examination and payment.

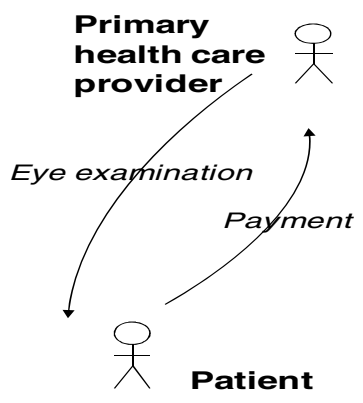

Fig. 2. A simple value model

\subsection{Task 2: Generate Technical KPIs}

Technical service quality focuses on technical accuracy and procedures, in particular the quality and effectiveness of the diagnostic and therapeutic intervention processes. In other words, technical service quality is about the results of health services and the consequences of health issues. A number of top level goals for technical service quality are:

1. Health care services should have positive effects on health issues

2. Secondary diseases should be avoided

3. Health issues should be treated by evidence based health care services

4. Health care services should not give rise to unwanted side effects

In order to measure the fulfillment of these goals, we introduce four generic KPI templates, each addressing one of the goals. When instantiated, these templates will result in a set of KPIs. 
The generic KPI templates are:

1. Percentage of health care service $x_{1}$ that is followed by health care service $x_{2}$

2. Percentage of health issue $y_{1}$ that is followed by health issue $y_{2}$

3. Percentage of health issue $y_{1}$ that is followed by health care service $x_{1}$

4. Percentage of health care service $x_{1}$ that is followed by health issue $y_{1}$

In order to instantiate these templates, relevant health care services and health issues need to be chosen. As this choice depends on the health care scenario under consideration, KPI designers need an instrument for documenting and representing the health care services and health issues they decide to include. When they have done so, they can go on to instantiating the KPI templates to arrive at KPIs. We suggest that relevant health care services and health issues should be represented by a simple conceptual model, called a service and issue model (SIM). Such a model consists of two classes, Health Care Service and Health Issue as well as a number of subclasses of these. The subclasses included in a SIM will depend on the health care scenario being addressed and will, therefore, vary from scenario to scenario.
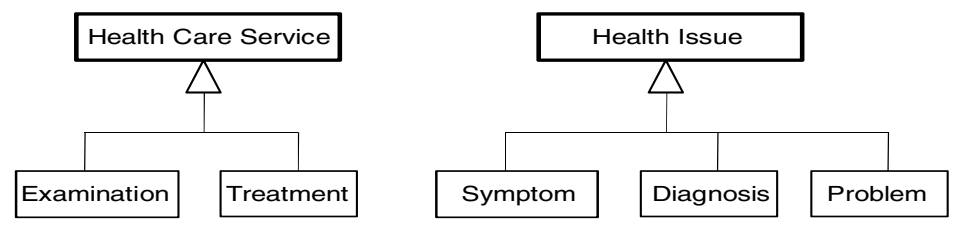

Fig. 3. The standard SIM

In Fig. 3, we suggest a standard SIM, based on notions from CONTSYS [14], that should be applicable in many scenarios with no or minor modifications.

The method for designing KPIs for technical service quality can now be formulated in three steps:

\section{Step 1: Adapt Standard SIM}

Construct a SIM. This can be done by modifying the standard SIM of Fig. 3. Fig. 4 shows an example of such a SIM, adapted from the standard SIM.

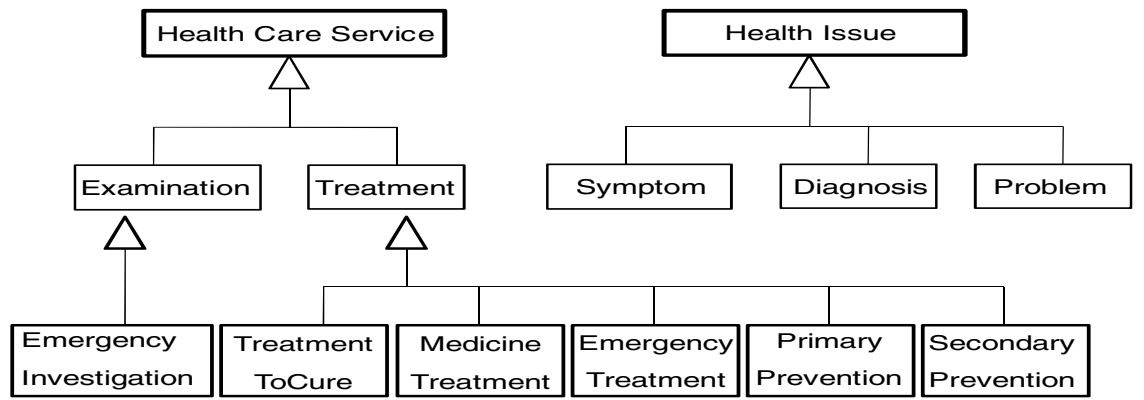

Fig. 4. A SIM, adapted from the standard SIM described in Fig. 3 


\section{Step 2: Apply Generic KPI Templates}

For each of the four generic KPI templates (presented above) and every subclass X of Health Care Service in SIM (see Fig. 4) and every subclass Y of Health Issue in SIM (see Fig. 4), introduce a new specific KPI template by replacing every $\mathrm{x}_{\mathrm{i}}$ (in the generic KPI templates) with $\mathrm{X}$ and every $\mathrm{y}_{\mathrm{i}}$ (in the generic KPI templates) with Y. Each such template will have the form "Percentage of $\mathrm{X}$ that is followed by $\mathrm{Y}$ ", where $\mathrm{X}$ and $\mathrm{Y}$ are classes in SIM.

An example of a specific KPI template, based on KPI template 1 and the SIM in Fig. 4, is:

- Percentage of primary prevention that is followed by secondary prevention

An example of a specific KPI template, based in KPI template 3 and the SIM in Fig. 4, is:

- Percentage of diagnosis that is followed by a medicine treatment

The created specific KPI templates can also by themselves be used as KPIs.

\section{Step 3: Apply specific KPI templates}

For every specific KPI template from Step 2, "Percentage of X that is followed by Y", replace $\mathrm{X}$ and $\mathrm{Y}$ with instances of these classes. This replacing can be carried out in two ways:

a) A domain expert examines every specific KPI template and replaces X and $\mathrm{Y}$ with instances based on her knowledge.

b) A domain expert populates the SIM with instances. A list of all possible KPIs is then generated automatically. Finally the domain expert selects relevant KPIs from the list.

Two examples of KPIs, created from the specific KPI template "Percentage of diagnosis that is followed by medicine treatment", are:

- Percentage of flu diagnosis that is followed by Tamiflu treatment

- Percentage of stroke diagnosis that is followed by warfarin treatment

After having applied these steps, the KPI designer will have arrived at a number of KPIs that focus on the results and consequences of health care services and health care issues. These KPIs are objective in the sense that they do not primarily depend on the assessments of patients.

\subsection{Task 3: Generate Functional KPIs}

While technical service quality focuses on the effects of health care services, functional service quality refers to the manner in which services are delivered to the patient. Functional service quality includes aspects like facilities, hospital food, employee attitudes, responsiveness, and cleanliness. While technical service quality is typically difficult to judge for the individual patient, functional service quality is usually directly visible to the patient. Therefore, functional service quality often has more impact on a patient's service quality perception than technical service quality.

In contrast to technical quality, functional quality does not depend only on health care services but also on complementary services, like ordering, information and complaint services. We have identified a number of complementary service types, based on an adaptation of the open-EDI phases [15]. Note that one of the open-EDI phases, 
i.e. actualisation, has been excluded as it corresponds to the original service, i.e. the service for which the complementary services are identified.

The complementary services identified are the following:

\section{Identification}

An identification service offered by a health care provider is an information service that provides information about the provider's services and helps a patient in identifying and selecting among health care providers and their services.

\section{Negotiation}

A negotiation service offered by a health care provider is an interactive service where the patient and the health care provider negotiate in order to arrive at an agreement on a future health care service including its cost, scheduling, location and personnel.

\section{Pre-actualisation}

A pre-actualisation service offered by a health care provider is an information service where the health care provider informs the patient on adequate preparations for a health care service.

\section{Post-actualisation}

A post-actualisation service offered by a health care provider is either

a) an information service where the health care provider informs the patient on the result of a health care service

b) an information service where the health care provider informs the patient on adequate behaviour to be carried out or observed by the patient after the performance of a health care service

c) a service where the health care provider accepts and addresses complaints on a health care service

Both health care services and their complementary services should be assessed along a number of service dimensions. Thus, a KPI designer is to select a set of service dimensions and for each service dimension, one or several service items. Which service dimensions and items to investigate depend on the health care scenario under consideration. We envisage that in most cases, the service dimensions will be variations or extensions of those in SERVQUAL or its predecessor. Furthermore, for each service item and each type of service (including complementary service types), the KPI designer shall specify how significant the service item is for that type of service. A service item is significant for a service type if it is important for a patient's perception of services of that type and if it is difficult for the health care provider to score well on the item. Only if both these conditions are satisfied, it becomes interesting to measure the item through KPIs.

Summarising, the KPI designer shall define a service dimension model (SDM), consisting of a set of service dimensions; for each service dimension, a number of service items; and for each combination of service item and complementary service type, the significance of the service item for the service type. A SDM can be represented as a matrix, see Table 1.

We do not believe there exists a canonical SDM that is optimal for each health care scenario. However, we envisage that most SDMs will share large parts. Therefore, it is worthwhile to introduce a standard SDM that can serve as a starting point when a KPI 
designer develops her own model for a particular scenario. For this purpose, we suggest the standard SDM in Table 1, based on the predecessor to SERVQUAL, where we have indicated significance on a three level scale: zero, one or two + marks. The significance marks of the model are justified as follows:

Reliability is less important for identification and negotiation services partially because no promises have been made before these services, thereby making the question of faithful service execution irrelevant. Consistency of performance and prompt attention to defect service are particularly important for actualisation, as these directly influence the health state of patients.

Responsiveness is important in all phases, as customers value prompt services and willingness during their entire episodes of care.

Competence is particularly important for actualisation, as it directly influences the health state of patients. It is also important for the pre- and post-actualisation phases, where it also has a strong impact on health state. Competence is less important for the identification and negotiation phases, as the competence needed for these activities is relatively easy to achieve.

Access is particularly important for identification and negotiation services, as the use of these services potentially may be stressful and take a long time. Good access may reduce stressfulness as well as time consumption for patients.

Courtesy is important in all phases, as customers value a positive attitude and privacy during their entire episodes of care.

Communication is especially important in pre- and post-actualisation phases, as these involve much patient interaction and may have substantial impact on the health state as well as the feeling of safety of the patient.

Understanding the customer is important in all phases, as health issues are complex and dependent on the individual patient. Therefore, customised services are often needed in health care.

Tangibles are of interest when services are given at health care facilities by health care personnel, i.e. in the actualization phase, as well as in the pre- and postactualisation phases. Visual appeal of physical facilities and cleanliness of employees will indicate that the health care provider offers high quality services. However, a wellstructured web page is also of importance in the identification and negotiation phases.

The method for designing KPIs for functional service quality can now be formulated in three steps.

Step 1: Identify Complementary Services

For each service from the value model, introduce complementary services according to the complementary service types above.

Step 2: Adapt the Standard SDM

Construct a SDM. This can be done by modifying the standard SDM of Table 1.

\section{Step 3: Apply the SDM}

For each health care service and complementary service from Step 1, apply the SDM from Step 2, i.e. identify for each service item zero or more KPIs. The significance of a service item for a service type will assist in determining whether to introduce a KPI or not. 
Table 1. The standard SDM

\begin{tabular}{|c|c|c|c|c|c|c|c|}
\hline & $\begin{array}{l}\text { Actua- } \\
\text { lisation }\end{array}$ & $\begin{array}{l}\text { Identi- } \\
\text { fication }\end{array}$ & $\begin{array}{l}\text { Nego- } \\
\text { tiation }\end{array}$ & $\begin{array}{l}\text { Preac- } \\
\text { tualisa- } \\
\text { tion }\end{array}$ & \begin{tabular}{|l|} 
Post- \\
actualisa- \\
tion \\
-result
\end{tabular} & \begin{tabular}{|l|} 
Post- \\
actualisa- \\
tion \\
-behavior
\end{tabular} & \begin{tabular}{|l|} 
Post- \\
actualisa- \\
tion \\
complains
\end{tabular} \\
\hline \multicolumn{8}{|l|}{ RELIABILITY } \\
\hline consistency of performance & ++ & & & + & & + & + \\
\hline correct keeping of records & + & & & & + & + & + \\
\hline correct billing & $\mathrm{N} / \mathrm{A}$ & $\mathrm{N} / \mathrm{A}$ & $\mathrm{N} / \mathrm{A}$ & $\mathrm{N} / \mathrm{A}$ & $\mathrm{N} / \mathrm{A}$ & $\mathrm{N} / \mathrm{A}$ & + \\
\hline on-time (promised) delivery & + & $\mathrm{N} / \mathrm{A}$ & $\mathrm{N} / \mathrm{A}$ & + & + & + & + \\
\hline prompt attention to defect services & ++ & & & + & + & + & + \\
\hline \multicolumn{8}{|l|}{ RESPONSIVENESS } \\
\hline prompt service delivery & + & + & + & $\begin{array}{llll}+ & & l & 0\end{array}$ & + & + & + \\
\hline $\begin{array}{l}\text { exact information on service delivery } \\
\text { time }\end{array}$ & + & $\mathrm{N} / \mathrm{A}$ & $\mathrm{N} / \mathrm{A}$ & + & + & + & + \\
\hline employee willingness to help & + & + & + & + & + & + & + \\
\hline $\begin{array}{l}\text { employee willingness to help when } \\
\text { busy }\end{array}$ & + & + & + & + & + & + & + \\
\hline calling the customer back quickly & + & + & + & + & + & + & + \\
\hline \multicolumn{8}{|l|}{ COMPETENCE } \\
\hline knowledge and skill of the personnel & ++ & & & ++ & ++ & ++ & ++ \\
\hline education level of the personnel & ++ & & & + & + & + & \\
\hline experiences of the personnel & ++ & & & + & + & + & \\
\hline $\begin{array}{l}\text { research capability of the organisa- } \\
\text { tion }\end{array}$ & + & $\mathrm{N} / \mathrm{A}$ & $\mathrm{N} / \mathrm{A}$ & & & & $\mathrm{N} / \mathrm{A}$ \\
\hline \multicolumn{8}{|l|}{ ACCESS } \\
\hline $\begin{array}{l}\text { easy access to services by phone, } \\
\text { web and mail }\end{array}$ & & ++ & ++ & & & & \\
\hline short waiting time to receive service & ++ & ++ & ++ & ++ & ++ & ++ & ++ \\
\hline convenient hours of operation & + & ++ & + & + & + & + & + \\
\hline convenient location of service facility & + & & & & & & \\
\hline \multicolumn{8}{|l|}{ COURTESY } \\
\hline $\begin{array}{l}\text { attitude of employee in performing } \\
\text { the service }\end{array}$ & + & ++ & ++ & + & + & + & ++ \\
\hline high level of privacy & ++ & ++ & ++ & $\mathrm{N} / \mathrm{A}$ & ++ & $\mathrm{N} / \mathrm{A}$ & \\
\hline COMMUNICATION & & & & & & & ++ \\
\hline $\begin{array}{l}\text { understandable explanation of the } \\
\text { service }\end{array}$ & & & + & ++ & ++ & ++ & ++ \\
\hline $\begin{array}{l}\text { understandable explanation of cost } \\
\text { and trade-offs between service and } \\
\text { costs }\end{array}$ & $\mathrm{N} / \mathrm{A}$ & $\mathrm{N} / \mathrm{A}$ & ++ & $\mathrm{N} / \mathrm{A}$ & $\mathrm{N} / \mathrm{A}$ & $\mathrm{N} / \mathrm{A}$ & ++ \\
\hline patient interaction & + & & + & + & ++ & + & + \\
\hline continuous state updates & + & $\mathrm{N} / \mathrm{A}$ & $\mathrm{N} / \mathrm{A}$ & + & + & + & + \\
\hline \multicolumn{8}{|l|}{$\begin{array}{l}\text { UNDERSTANDING/ } \\
\text { KNOWING THE CUSTOMER }\end{array}$} \\
\hline \begin{tabular}{|lll} 
learning the customer's specific \\
requirements
\end{tabular} & ++ & + & ++ & ++ & ++ & ++ & + \\
\hline providing individualised attention & ++ & + & ++ & ++ & ++ & ++ & + \\
\hline \multicolumn{8}{|l|}{ TANGIBLES } \\
\hline up-to-date equipment & + & $\mathrm{N} / \mathrm{A}$ & $\mathrm{N} / \mathrm{A}$ & $\mathrm{N} / \mathrm{A}$ & $\mathrm{N} / \mathrm{A}$ & $\mathrm{N} / \mathrm{A}$ & $\mathrm{N} / \mathrm{A}$ \\
\hline visual appeal of physical facilities & + & & & & + & & \\
\hline $\begin{array}{l}\text { well dressed and neat appearance } \\
\text { of employees }\end{array}$ & + & & & & + & & \\
\hline $\begin{array}{l}\text { consistency between the appear- } \\
\text { ance of physical appearance and } \\
\text { type of services provided }\end{array}$ & + & & & & + & & \\
\hline cleanliness of employees & ++ & & & & + & & \\
\hline cleanliness of physical facilities & ++ & & & & + & & \\
\hline web page & & ++ & + & & & & \\
\hline
\end{tabular}




\section{Method Application}

In this section, the proposed method is applied for demonstration purposes. The method is applied on the results from a research project (REMS) in the eye health care domain in Stockholm [16]. The main aim of the project was to develop and evaluate a set of e-services that could be used to create, manage and transfer health care referrals between primary health care and eye specialist providers. In the project, a set of enterprise models were constructed to support the design and evaluation of the eservices. Some of these models are used in this section.

\section{Task 1: Develop Value Model}

The first task in the proposed method is to delimit the domain for which the KPIs are to be designed, i.e. specify which services need to be measured using KPIs. For that purpose, a value model is constructed. In this case, a part of a value model from the REMS project is used, see Fig. 5.

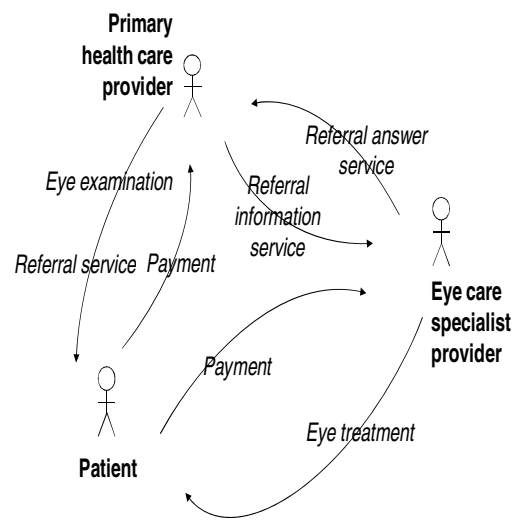

Fig. 5. A value model from the REMS case showing actors and resource transfers

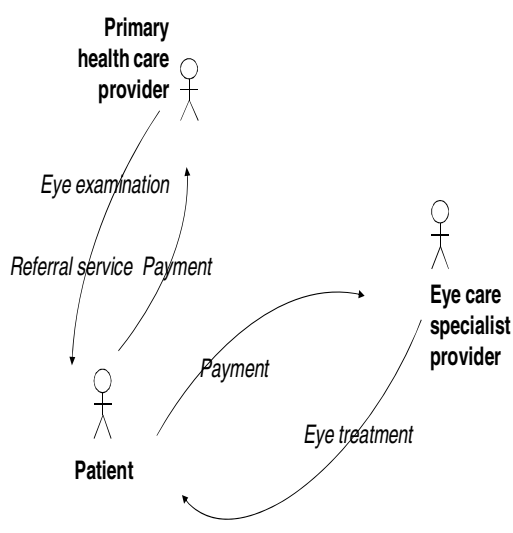

Fig. 6. The value model from the perspective of the patient

The value model in Fig. 5 shows three actors - patient, primary health care provider and eye care specialist provider - and the transfers of resources between them. The background of the value model is the following: When a patient experiences an eye health problem, she/he will visit the primary health care provider. The basic resource this provider offers is an eye examination service. In order to receive that service, the patient needs to pay a certain fee for the service. The fee transfer is carried out via a payment service. If the patient needs further treatment, either the primary care provider will carry out the treatment (which is not shown in Fig. 5) or the provider refers the patient to an eye care specialist provider who is able to provide advanced treatment services. To do this, the primary health care provider transfers a referral via a referral service to the patient, which allows her to be treated by an eye care specialist provider. The primary care provider will also transfer referral information via a referral information service to the eye specialist provider, which will be used for scheduling a treatment service for the patient, as well as being the base for 
resource allocation. The eye care specialist provider offers an eye treatment service to the patient and the patient needs to transfer a fee via a payment service. After the treatment service is carried out, the eye care specialist provider will transfer a referral answer service to the primary health care provider, informing it about the result of the treatment.

In the method proposed in this paper, only KPIs from the perspective of the patient are to be generated. Therefore, only resourced transferred to and from the patient are included. This will delimit the value model further, see Fig. 6.

\section{Task 2: Generate Technical KPIs}

In order to generate the KPI for measuring technical service quality, three steps are to be carried out.

\section{Step 1: Adapt Standard SIM}

In this step, the standard SIM, see Figure 3, is to be adapted to the value model constructed in task 1 . In other words, the standard SIM has to include all the health care services from the value model, but not other types of services, such as administrative and resource allocation services. For example, the value model in Fig. 6 includes two health care services, eye examination and eye treatment, which are to be included in the SIM, see Fig. 7.

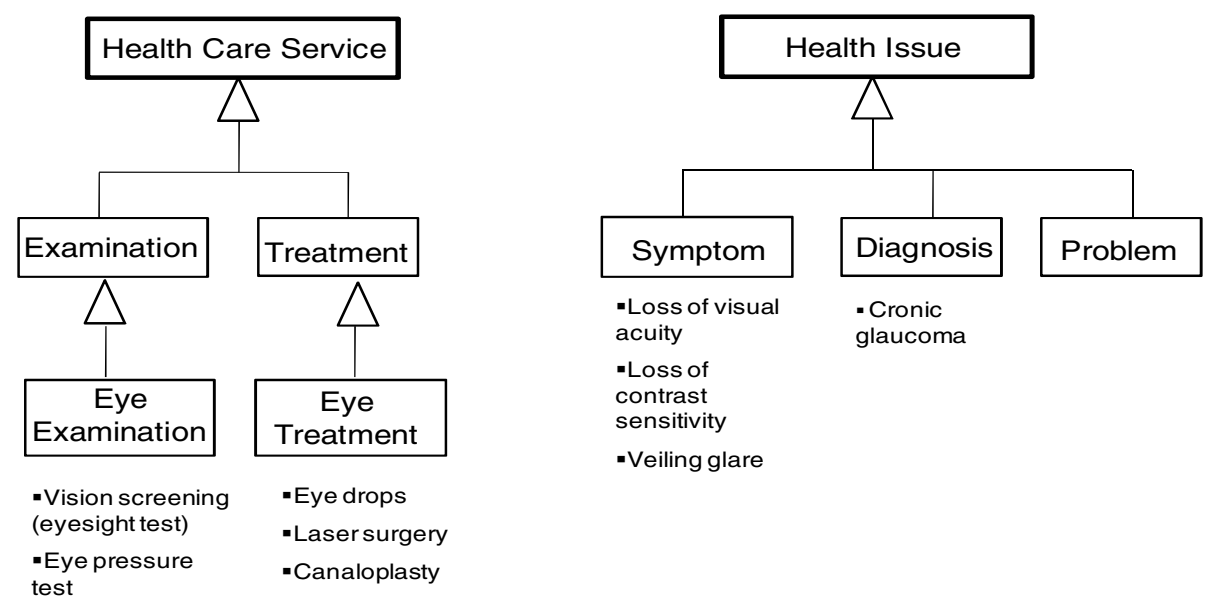

Fig. 7. A SIM with concepts (subclasses) based on the information from the value model. Examples of instances of the concepts are also shown.

\section{Step 2: Apply Generic KPI Templates}

In this step, the four generic KPI templates presented in section 3.2 are to be instantiated by the concepts (subclasses) of the SIM from step 1, in order to create a set of specific KPI templates. There are seven concepts in the adapted SIM in Fig.7. However, the more generalised concepts examination and treatment will not be used in this step but only their specialised concepts, eye examination and eye treatment. For example, the generic KPI template 4: "Percentage of health care service $\mathrm{x}_{1}$ that is followed by health issue $\mathrm{y}_{1}$ " can be instantiated by the health care service eye treatment 
and the health care issue symptom from the adapted SIM. This will result in a specific KPI template: "Percentage of health care service eye treatment that is followed by health issue symptom".

\section{Step 3: Apply Specific KPI Templates}

In this step, the resulting specific KPI templates from step 2 need to be instantiated by a set of instances from the SIM. This requires that the SIM in Fig. 7 be instantiated. Examples of instances of the SIM can also be found in Fig. 7. These 9 instances are applied on the specific KPI templates, resulting in a number of KPIs. For example, the template constructed in the previous step, "Percentage of health care service treatment that is followed by health issue symptom", can be instantiated by the treatment eye pressure test and the symptom veiling glare. This will result in the KPI "Percentage of health care service eye pressure test that is followed by health issue veiling glare".

\section{Task 3: Generate Functional KPIs}

In order to generate KPIs for measuring functional service quality, three steps are to be carried out.

\section{Step 1: Identify Complementary Services}

In this step, the complementary services are applied on each service in the value model, both health care services and other services. For example, the service eye examination will have four complementary services: identifying an eye examination service, negotiating an eye examination service, pre-actualising as well as postactualising an eye examination service.

\section{Step 2: Adapt the Standard SDM}

In this step, the standard SDM, see Table 1, is adapted. This is done by adding, deleting or changing the dimensions and items of the standard service dimension model. In this example case, we do not make any changes to the standard service dimension model but keep it as is.

\section{Step 3: Apply the adapted Service Dimension Model}

For each service identified in Step 1, we consider all the service dimensions and service items in the SDM from Step 2. For each item, we determine whether to include some KPI or not. For example, for the (complementary) service "pre-actualising an eye examination" and the service item "understandable explanation of the service", we introduce a KPI based on the following question to a patient "Did you get an understandable explanation of how to prepare for your eye examination?"

\section{Concluding Remarks}

In this paper, we have proposed a method for designing KPIs for a health care organisation with a focus on patient oriented KPIs. The starting point of the method is a value model that delimits the domain under consideration by identifying health care actors and resource transfers, including services. Based on the services identified, the method helps to generate KPIs for both technical and functional service quality. Technical quality KPIs measure the results of health services and the consequences of health issues and are generated by considering a small number of top level goals for 
technical quality. Functional quality KPIs refer to the manner in which health care services are delivered to patients and are generated by identifying complementary services and applying dimensions from the predecessor to SERVQUAL. This way of generating KPIs can also be seen as goal driven, as the dimensions of the predecessor to SERVQUAL and its items express subgoals of high level goal customer satisfaction.

The proposed method provides four main advantages:

Ease of Design. Designing a set of KPIs for a health care scenario is a complex and time consuming task. The proposed method alleviates this task by offering a designer a large number of potential KPIs from which she can choose the most relevant ones.

Completeness. A problem in KPI design is to ensure that all relevant KPIs have been identified, i.e. to ensure the completeness of the KPIs. The proposed method addresses this problem by systematically generating relevant KPIs for technical as well as functional quality.

Traceability. KPIs should be possible to justify by relating them to the goals whose fulfillment they measure, i.e. KPIs should be traceable to goals. The proposed method provides traceability by directly generating potential KPIs from goals, which in the case of functional quality are expressed through SERVQUAL dimensions and items.

Flexibility. The health care scenario under consideration will influence the choice of KPIs, meaning that a KPI designer needs to be able to describe the specifics of a certain scenario in a convenient way. The proposed method supports this description through the use of value models, SIMs and SDMs, where the KPI designer can describe the most important health care services and health issues as well as relevant service items and their prioritisation.

In this paper, we have only addressed technical and functional service quality. However, a third aspect of service quality is the effect a health service can have on the quality of life of a patient, including the physical, psychological and social functioning of the patient. A direction of future work is to design guidelines for identifying KPIs for this service aspect. This requires measuring how well a patient functions in daily life during an extended period of time, e.g. how often the patient makes or receive phone calls to friends and family.

Another direction of future work is to provide support in actually formulating KPIs for functional quality. The method presented only suggests service items for different services that should be measured by KPIs but does not suggest formulations of these KPIs. We believe that it is possible to find such formulations for a large proportion of the service items.

Finally, only KPIs from the patient's perspective are generated. Future work will also include generation of KPI from the health care providers' perspective, such as revenue and cost efficiency.

Acknowledgements. The research described in this paper was partly funded by the Swedish agency for innovation system (VINNOVA). 


\section{References}

1. Walburg, J.: The outcome quadrant. In: Walburg, J., Bevan, H., Wilderspin, J., Lemmens, K. (eds.) Performance Management in Health Care. Improving patient outcomes: an integrated approach. Routledge, UK (2006)

2. Eckerson, W.: Performance Dashboards. In: Measuring, Monitoring and Managing Your Business, John Wiley, Chichester (2006)

3. Jun, M., Peterson, R.T., Zsidisin, G.A.: The identification and Measurment of Quality Dimension in Health Care: Focus Group Interview Results. Health Care Management Review 23(4), 81-96 (1998)

4. Adair, C.E., Simpson, L., Birdsell, J.M., Omelchuck, K., Casebeer, A.L., Gardiner, H.P., Newman, S., Beckie, A., Clelland, S., Hayden, K.A., Beausejour, P.: Performance Measurement Systems in Health and Mental Health Servicws: Models, Practices and Effectiveness. A State of the Science Review. The Alberta Heritage Founddation for Medical Research (2003)

5. Grönroos, C.: A Service Quality Model and Its Marketing Implication. European 18(4), 36-44 (1984)

6. Parasuraman, A., Zeithaml, V.A., Berry, L.L.: SERVQUAL: a multiple-item scale for measuring consumer perception of service quality. Journal of Retailing 64(1), 12-40 (1988)

7. Parasuraman, A., Zeithaml, V.A., Berry, L.L.: A conceptual model of service quality and its implication for future research. Journal of Marketing 49(4), 41-50 (1985)

8. Gupta, H.D.: Identifying Health Care Quality Constituents: Service Providers' Perspective. Journal of Management Research 8(1) (2008)

9. Kilbourne, W.E., Duffy, J.A., Duffy, M., Giarchi, G.: SERVQUAL in cross-national measurements of health care quality. Journal of Service Markeing 18(7), 524-533 (2004)

10. Karassavidou, E., Glaveli, N., Papadoupoulos, C.T.: Quality in NHS hospitals: no one knows better than patients. Measuring Business Excellence 12(1), 34-46 (2009)

11. Gill, L., White, L.: A critical review of patient satisfaction. Leadership in Health Services, vol. 22(1), pp. 8-19. Emerald Group Publishing (2009)

12. Kartseva, V., Hulstijn, J., Gordijn, J., Tan, Y.-H.: Control Patterns in a Healthcare Network. In: Brnong, A., and Janssen, M. (eds.) Proceedings of the 8th Annual International Conference on Digital Government Research (DGO 2007), Digital Government Research Center, pp. 66-75 (2007)

13. Johannesson, P., Perjons, E.: Managing Complexity through Value Modeling. Healthcare IT Management 4(2) (2009)

14. CONTSYS, EN-13940-1:2007, Health Informatics - Systems of concepts to support continuity of care. Part 1: Basic Concepts (2007)

15. UN/CEFACT Modeling Methodology User Guide, http: / / www . unece.org/cefact/

16. Henkel, M., Johannesson, P., Perjons, E., Zdravkovic, J.: Value and Goal Driven Design of E-Services. In: The IEEE International Conference on e-Business Engineering (ICEBE 2007), Hong Kong, China, October 24-26, pp. 295-303 (2007) 